\title{
Autochthony and Deracination: Knowledge and Translation
}

\author{
SUSHANT KUMAR MISHRA
}

The paper attempts to explain the concepts of autochthony and rootedness of knowledge in a particular culture and then further explains how the knowledge of one culture may get transmitted to the other cultures. The processes of this 'deracination' of knowledge rooted in one culture are not simply a process of transfer of knowledge. Its travel and then implantation in another culture is rather a complex process in which translation plays an important role. Etymologically, the notion of translation itself may be understood as 'taking (ideas) across'. In history and in contemporary times, this 'translation' of knowledge and cultural narratives and texts has been a complex process. This paper aims at understanding some of the intricacies of this process.

Keywords: autochthony, evolution of knowledge, culture, ideas, transformation, translation

Knowledge is contained in the source texts of a culture. These texts are often not available in written form for all cultures of the world - most of the peoples lack the written sources for their cultural knowledge. Few cultures in the world have achieved such advanced forms of communication that they could retain their cultural knowledge in written forms. Foremost among such cultures with vast amount of knowledge expressed in various cultural forms have been the Greek and Indian cultural forms. These two cultural expressions have contributed largely to the world of today. Greeks contributed through the Latin and the Arabs. Hebraic cultural knowledge also has been communicated to us through Greeks - the Bible has been transformed from Hebrew to Greek giving rise to such a tradition that the New Testament was originally written in Koine Greek, an important dialectal form of old Greek. Arabic culture also retained and maintained the cultural forms received from the Hebraic and later from Greek sources and perhaps the knowledge contributed a lot to the advancement and evolution of the Arabic world for centuries. However, somewhere the scientific spirit did not profoundly touch the Arabic world which yielded to the modern world. The Arabic tradition of knowledge since twelfth century onwards got overshadowed by the European scientific and philosophical enquiries. The Indian tradition has also evolved continuously and a lot of knowledge is still maintained in the folk traditions of India despite a noticeable discontinuity in the knowledge traditions for centuries. Such folk traditions exist in almost all parts of the world which exhibit the culturally accumulated knowledge 
parallel to the scientific spirits of contemporary times. It may be worth investigating the processes of creating and maintaining the knowledge traditions of such traditions which are still often maintained along with the scientific knowledge of our times.

Let us first try to understand what we may call the knowledge societies. According to the UNESCO publication Towards Knowledge Societies, "a knowledge society is a society that is nurtured by its diversity and its capacities" (Jerome 2005). This diversity and the capacities presume the varieties of cultural forms which contain the knowledge expressed in various ways thus exhibiting the capacities of a particular society to perform the same or the similar functions with varied skills. Though the term 'knowledge society' may be recent, the societies with knowledge have existed since times immemorial. The UNESCO document in its opening lines asks, "Does the aim of building knowledge societies make any sense when history and anthropology teach us that since ancient times, all societies have probably been, each in its own way, knowledge societies?" (http://unesdoc.unesco.org). In what way, each society since the beginning may be considered a 'knowledge society'? The obvious answer is that the societies have mostly shared their knowledge systems with various groups and various other societies and hence the societies in general have been knowledge societies almost everywhere in the world. In almost every social system, we find that the shared knowledge belongs often to particular groups. As for example, the knowledge with the groups of artisans is shared mostly among the members of their own groups. Similarly the knowledge of various forms of artistic expressions or philosophical ideas is often confined to particular groups and is shared only on certain occasions. What could be the mode of sharing this knowledge? One possible mode would be obviously translating the knowledge in such linguistic forms that may be accessible to the other group or the other groups. In the context of India, we may find that there have been various movements to discuss, debate and share the knowledge traditions into various linguistic forms. We may cite, for example, the Bhakti tradition which often belongs to some philosophical sects originating in Sanskrit and similar other languages of the past. Even the Pali texts were the older knowledge traditions for the Bhakti tradition. The languages had evolved and similarly the communication of ideas needed to evolve. This evolution has always taken place in the Indian context - however rigidity one may try to find in certain cultural groups, the evolution never ceased to exist. Even the stories of Ram were written for various linguistic groups. Similarly the folk knowledge of each social group was venerated - the people of each area respectfully rendered the tradition of theatrical cultural forms with all possible variations. The variations were understood and sympathetically appreciated. Whenever a new cultural form emerged, the societies did not try to throttle it nor were there very successful attempts to submerge the new cultural form into an existing one. As for example, we may find the dance and theatre forms evolving in Assam since the times of Mahapurush Srimant Sankardeva which 2 
were recognized and respected by people. Similar artistic forms emerged in various parts of India and gradually the practitioners of such cultural forms were accepted as artists and saints who often had high social status.

Similar situation may be found in India during the times of Buddha. There were several contemporaries of Buddha like the Jain Tirthankaras and thinkers of the sect of Ajivikas who helped in transforming the existing thought processes and in bringing the existing thought processes closer to people by using the contemporary language forms. The older forms of Sanskrit had evolved so much that the language of ordinary speech had changed a lot and the people had started forgetting the language of the earlier texts. The language scholars had started working on the language forms and various systems of thought had started evolving since around three or four centuries prior to Buddha. As for example, the Mimamsa system of philosophy or several Vedangas evolved to investigate and understand the language of the Vedas. As writes Ashit Chakraborty, "...the Vedangas i.e. auxiliary Sciences such as Sikshaa (Phonetics), Chandas (Metre), Vyakarana (Grammar) and Nirukta (Etymology), were developed to fix the pronunciation and metre of the Vedic psalms and to devise elaborate procedure for understanding the Vedic texts. Grammar and etymology acquired an important place in the training of Vedic scholar" (Chakraborty 1976: 10). It is obvious that various branches of language studies, as known today under the umbrella discipline of Linguistics, developed. Even the scholars of Mimamsa system and commentators began to "explain incomprehensible passages of the Vedas. In this process all tried to lay down general principles regarding the comprehension of Vedic text. Here, with a surprising sense of realism, they also enunciated the principle that the method of comprehending a Vedic text, a text composed in a divine language, might as well be applied to any manmade, living language, the secular or Laukika texts" (Chakraborty 1976:10). Ashit Chakraborty in his book further argues for the sciences of Vyakarana and Nirukta as disciplines which elaborated in details upon the language studies. All these writings, as has been indicated here, involved the debates in the Translation Studies as they tried to explain, interpret and understand the purports of the selected texts of their own traditions in a language or in a particular variety of language that was comprehensible to the contemporary scholars. The earlier forms of knowledge contained in a language were continuously being preserved and made available to the contemporary generations of scholars as well as to the future generations. This is almost the similar efforts as are being done today in re-producing contemporary editions of Shakespeare and similar other great writers. These are several examples of efforts that may be classified as intra-lingual translational activities if we borrow the terminology from Roman Jakobson (Jakobson 1959). Such attempts to preserve and transfer knowledge through evolution of various linguistic and cultural forms are examples of attempts towards using the translation activities as tools for creating and maintaining a knowledge society in contemporary times. 
Indian society may not be an isolated example for employing translation activities for keeping the continuity of knowledge traditions. Societies east to India have exhibited similar tendencies. Japanese have not only translated the texts from various traditions of China and India but they have also further evolved on these traditions. The Buddhist texts as available in Japanese today have been the foundational texts of the knowledge systems of Japanese people. Isolated in various islands, they continued to translate and allowed the knowledge systems of distant lands to grow and in the process the societies themselves evolved not only in terms of cultural and linguistic knowledge forms but also in terms of its scientific temper. It may be just an accident that in late $19^{\text {th }}$ Century, the Japanese society could start evolving so much that it could develop machines and other required infrastructure to start conceptualizing such political formations which could be achieved by Europe after long processes of historical evolution since the times of renaissance. A lot can be said to eulogise the economic and governance patterns evolved in Japan since fifteenth century. Yet we may have to concede to the fact that the high level of literacy or rather education that Japan had since centuries, due to its interactions with distant lands like China and India, made it a fervent ground for positively harnessing the industrial knowledge that came to Japan during its interactions with the European world. As may be cited, "Japan was well positioned to take up the Western challenge. It harnessed its infrastructure, its high level of literacy, and its proto-industrial distribution networks to the task of emulating Western organizational forms and Western techniques in energy production, first and foremost enlisting inorganic energy sources like coal and the other fossil fuels to generate steam power" (https://eh.net/encyclopedia/japanese-industrialization-and-economic-growth/). Though the role of high levels of literary and its direct link to the cultural practices related to knowledge percolation to various levels of society is yet to be studied thoroughly, it may not be very odd to conjecture that the rich knowledge and mainly the translation traditions for reception and enrichment of local knowledge traditions may have given the intellectual acumen to the Japanese people to quickly adapt and use the knowledge of the European science and technology to establish a strong military-industrial state. It is not surprising that with such flexible and fertile knowledge tradition deeply grounded in translation activities could think of a slogan like fukoku kyohei (wealthy country/strong military). The Japanese society could not only think of it as a slogan but could also actively work towards achieving such goals in the nineteenth century itself, much before the European nations which had actually evolved the philosophy and political structure for military-industrial power based nation states (Obispo 2017).

Such examples, as discussed above, bring us some challenges in understanding the issues of knowledge traditions within autochthonous groups and how other knowledge traditions borrowed from other autochthonous groups help them evolve. A knowledge tradition which travels out of its territory may be irrelevant in a new territory or in new chronological 4 
conditions. Yet, the above examples are indicative of the fact that in spite of the territorial or chronological relocation, the knowledge tradition available to new societies through translatorial enterprises not only gets conditioned to these societies but also helps such societies evolve further in their own pursuit of knowledge. This is indeed apparently a strange fact that the knowledge which is rooted in a tradition can get deracinated and can be found with deep roots later on in other cultural forms in far off lands. Cultural interactions have often happened in this process - yet perhaps not all cultures have really spread with their knowledge base. As for example, the spread of the Arab culture initially led to the creation of strong centres of learning and scholarship and yet these strong centres gradually disappeared without any apparent military or direct economic invasions from other places. Though the cultural knowledge evolved during centuries did contribute in evolution of many other cultures, the basic cultural knowledge in terms of various scientific, technological and other philosophical innovations did not grow. And the autochthonous Arabic speaking societies remained untouched by the technological revolutions and evolution of military-industrial governing power as we notice in the case of Japan. This is a historical fact that the Arabic speaking peoples have strong traditions of translation from various sources, at least during the initial centuries of its expanding military might. However, perhaps the reason for relatively lesser expansion of knowledge base and lesser evolution of science and technology is that a great emphasis was laid upon the expansion of political-military power, along with religion which functioned as an important tool for the this end, and as a consequence, the overall research in the field of science and technology gradually diminished. This was not the case in Japan which continuously engaged itself not only in the research of science and required technology related to the interaction of its people with the high oceans but also continuously engaged itself in the philosophical and evolutionary religious debates and practices. This allowed them perhaps a greater maneuverability in adapting to the challenges coming from European brethrens since approximately sixteenth century. Even though the Europeans arrived with new technology like use of firearms and also with new business and religious models, the Japanese population could adjust itself perhaps because it was accustomed to engaging with several other cultural centres of the world. And the translation had played an important role in it. The Arabic scholars could not perhaps understand how the Europeans gradually evolved on the knowledge which reached Europe through Arabic lands and mainly after the fall of Constantinople. The knowledge base in terms of scientific, religious, philosophical and such other fields of human enquiries arrived in Europe through Arabs and was further evolved by the European intellectual environment. This is also a time when we find a lot of translation into contemporary European languages from various ancient and contemporary languages of the world. 
It may be interesting to note here that both the Arabic and the European cultures were by and large guided by the Semitic religious principles and followed very organized religious systems which were very similar in nature. Yet, the Europeans with the influence of various knowledge traditions available to them from the societies of ancient past as well as from other parts of the world started challenging the authority of organized religious systems. In the Arabic societies, we hardly notice this. Both the European powers and the Arabic powers had involved religious expansion principles in their business or military expansionist enterprises and yet the reception of cultural and philosophical knowledge of various geographically and chronologically distant societies created such an environment that the authority of the existing dominant social classes was fruitfully intellectually challenged even in face of mechanisms like strong inquisition by the religious authorities and strong military might of the aristocratic class. The presence of such an intellectual atmosphere owes a lot to the indomitable courage and hard work of those who brought the knowledge from various traditions to the people of Europe and of course the translation would have certainly played an important role in this transfer of knowledge. Once they were fascinated by the knowledge of the ancient Greeks, the early Romans (the older Latin texts also exhibited a lot of Greek and other influences), the European intellectual centres started making efforts to understand the past, dead or alive, of other cultures as well. For example, the Rosetta stone was forgotten by the Egyptians and the Europeans made attempts to understand it (http://www.britishmuseum.org). The content of inscription on the Rosetta Stone was studied and it is obvious that such contents studied thoroughly would have provided some political insights for evolving new governance models at the time of its studies (Jason 2017).The decipherment process of such inscriptions which were written in scripts forgotten by the people proves a great amount of intellectual challenge encountering such challenges while acquiring such tools from all possible sources to stand up to such daunting tasks provide great intellectual advancement to a culture. This process requires a lot of acumen we study today in forms of Translation Studies (https://www.nsa.gov/newsfeatures).The fact that the text written in one or many forms of languages of yore has to be understood by those who primarily speak the contemporary languages involves several exercises in translation and translation studies.

An illustrative example from the studies of the Indian history may be illuminating in the context. The decipherment of Ashokan inscriptions, completely forgotten by people, helped re-create several aspects of the ancient Indian culture and civilization. Ashoka himself was perhaps recreated and brought to the knowledge of contemporary India with help of tools acquired by decipherment of the inscriptions left by Ashoka. Even today, such inscriptions are being found and being read (http://www.ijhssi.org). When James Prinsep would have first deciphered the inscriptions and read the Brahmi and Kharosthi scripts, lots of documents important for recreation of history would have been available to the colonial powers with which they 6 
could easily create any version of the history they wanted to create. And translation would have been the tool for this. This is just another example how the knowledge with chronologically remote autochthonous groups could be used in completely new and varied contexts for various purposes related to political and social engineering. Social scientists have started accepting the importance of language and translation issues in the sphere of framing such policies which are conducive to the overall development perspectives of a particular society. The very fact that books on social policies have started discussing issues related to translation is a sign of the attempts to understand the implications of transfer of knowledge from one linguistic group to the other linguistic group and the social issues involved in the process. Naomi Lendvai and David Bainton write, “...translation is not just about linguistic practices; it takes us well beyond issues about languages; it is a broader research agenda with sensitivities to culture, context, diversity, inequalities, ethics and politics" (Lendvai \& Bainton 2013: 116). Outlining the importance of understanding the processes of translation in transfer of knowledge, policy frameworks and ideas, they write further, "For policy scholars, translation is a capturing metaphor of the immense mobility of the policy process; moving/translating from decisions to practices; from normative to practical expression of policy; from research to policy, or, within the rise of the transnationalization of policy, the issue of policy transfer, the travelling of social policy ideas, discourses, policies and institutions from one context to another" (Lendvai \& Bainton 2013: 117). We know that the translator deals with the morphing and re-adjusting of ideas in various social and culture based knowledge environments. This is often the central issue in translation studies. It is perhaps in this sense that the texts written in a linguistically alienated environment are also often considered to be an aspect of 'cultural translation'. And since times immemorial the knowledge has transferred from one social context to the other through this process. This knowledge transfer itself may involve all the intricacies of linguistic and cultural variations central to the issues related to meaning generation. Often the scientific and technical knowledge systems are influenced by the cultural quests and norms for better life and newer means of livelihood. Translation and translation studies in this context offer deeper insights in the process of evolution and transfer of knowledge across societies in the world. In today's situation of globalization, often the knowledge systems travel throughout the world easily and the intricacies of translation processes have become important issues in transfer of knowledge systems. It may not be surprising to see how the technology and business experts of one culture learn to deal with their counterparts in the other culture - the present BPOs (Business Process Outsourcing enterprises) and collaborative technological enterprises provide immense challenges and opportunities for such studies. Institutions across the world tend to provide such courses which teach us how to conduct business in social environments of distant national and social groups. These are only 
indicative of how the knowledge systems evolved in one society travel and get implicated into the social processes of other societies of the world.

\section{References}

BINDÉ, JÉRÔME. 2005. Towards Knowledge Societies: UNESCO World Rep. Online: http://unesdoc.unesco.org/images/0014/001418/141843e.pdf

CHAKRABORTY, ASHIT. 1976. Translational Linguistics of Ancient India. Calcutta: Kanakdhara.

JAKOBSON, ROMAN. 1959. On Linguistic Aspects of Translation. Online: https://web. stanford.edu/ eckert/ PDF/jakobson.pdf

JoAnA, OBISPO. 2017. Japan's Fukoku Kyohei: A Continuous Pursuit of Economic and Military Powers. Online: http://www.sanbedaalabang.edu.ph/bede/images/ researchpublication/Ugong/ ugong2017vol960.pdf.

LENDVAI, NAOMI AND DAVID BAINTON. 2013. Translation: Towards a Critical Comparative Social Policy Agenda. In Kennett Patricia (ed.), A Handbook of Comparative Social Policy (second edition). Northampton: Edward Elgar Publication.

MOSK, CARL. Japan, Industrialization and Economic Growth. In Robert Whaples (ed.), EH.Net Encyclopedia. Online: http://eh.net/encyclopedia/ japanese-industrialization-and-economic-growth/.

URBANUS, JASON. 2017. In the Time of the Rosetta Stone. Online: https://www.archaeology.org/issues/274-1711/features/5997-egyptthmuis-rosetta-stone.

https://www.nsa.gov/news-features/declassified-documents/tech-journals/ assets/files/rosetta-stone.pdf. 